\title{
Urban-rural differentials in using antimicrobials at home among under-5 children with diarrhea
}

\author{
Shahnawaz Ahmed, Fahmida Dil Farzana, Farzana Ferdous, Mohammod Jobayer Chisti, \\ Mohammad Abdul Malek, Abu Syed Golam Faruque, Sumon Kumar Das
}

International Centre for Diarrhoeal Disease Research, Bangladesh

\section{Email address:}

shahnawz@icddrb.org(S. Ahmed), fahmidaf@icddrb.org(F. D. Farzana), farzanaf@icddrb.org(F. Ferdous), chisti@icddrb.org(M. J. Chisti), mamalek@icddrb.org(M. A. Malek), gfaruque@icddrb.org(A. S. G. Faruque), sumon@icddrb.org(S. K. Das)

\section{To cite this article:}

Shahnawaz Ahmed, Fahmida Dil Farzana, Farzana Ferdous, Mohammod Jobayer Chisti, Mohammad Abdul Malek, Abu Syed Golam Faruque, Sumon Kumar Das. Urban-Rural Differentials in Using Antimicrobials at Home among Under-5 Children with Diarrhea. Science Journal of Clinical Medicine. Vol. 2, No. 3, 2013, pp. 81-86. doi: 10.11648/j.sjcm.20130203.14

\begin{abstract}
Due to self-limiting course of disease, use of antimicrobials in childhood diarrhea should be limited; however, irrational use is widely reported and is considered as a potential challenge for controlling its rational use. Thus, the present study aimed to describe urban-rural differentials with regard to socio-demographic characteristics, clinical features, and etiologic distribution in antimicrobial use and identify predictors of its use at home before coming to the hospital. From the database (January, 2010 to December, 2012) of Diarrheal Disease Surveillance System (DDSS) of urban Dhaka Hospital and rural Matlab Hospital of icddr,b, we extracted relevant information of 4,245 under-5 children from Dhaka Hospital and 2,161 children from Matlab Hospital. In multivariate analysis, children from urban area were 1.53 times, children aged under 2 years were 1.31 times, better socio-economic status (monthly income $>100$ US\$) were 1.34 times, distance to health facility $>5$ miles from home 1.63 times, use of oral rehydration solution at home 2.95 times, duration of diarrhea $>24$ hours 4.25 times, frequency of stool $>10$ times/24 hrs. 1.47 times, abdominal pain 1.30 times and rotavirus infection were 1.54 times more likely to use antimicrobials at home before coming to the hospital (all $\mathrm{p}<0.05$ ). On the other hand, maternal illiteracy (OR-0.74), cough (0.83) and Vibrio cholerae infection (0.70) were less likely to influence antimicrobials use at home in study children (all $\mathrm{p}<0.05$ ). Socio-economic characteristics, clinical features, and etiologic agents of under-5 children determine use of antimicrobials at home before presenting to health facility.
\end{abstract}

Keywords: Antimicrobials, Diarrhea, Rural, Under-5 Children, Urban

\section{Introduction}

Use of antimicrobials against infection is the fundamental need for treating infectious diseases which makes the difference between cure and death or long-term disability [1]. Unfortunately, irrational uses of antimicrobials due to easy availability, low cost, and usage for shorter duration and inadequate amount are major public health concerns due to rising expansion of resistant microbes [1]. Not only the unlicensed healthcare providers but also licensed physicians often prescribe antimicrobials without considering possible etiology and disease severity [1]. Such practice is unwanted and often harmful [1]. According to World Health Organization, only $40 \%$ of patients in the public sector and $30 \%$ of patients in the private sector are treated following standard treatment guidelines with antimicrobials as primary care service in developing and transitional countries [2, 3]. However, frequent use has also been reported in developed countries [2]. It has been reported that in developing countries, at least $70 \%$ of pneumonia cases are treated rationally, while about $50 \%$ of all acute viral upper respiratory tract infections are treated with inadequate dosage of antimicrobials [4, 5].

Like other developing countries, Bangladesh has made substantial progress in antimicrobials manufacturing but its irrational use is badly affecting the health care delivery system [6]. A very recent study conducted in different levels of government health facilities revealed that only $34 \%$ licensed physicians prescribe antimicrobials in 
confirmed cases while $56 \%$ prescribe antimicrobials in suspected infections [6]. Almost $40 \%$ physicians prescribe antimicrobials in cold and fever without or before any laboratory confirmation [6]. The most alarming scenario was that, physicians often prescribed antimicrobials for better client satisfaction particularly of the parents [6]. However, there is scarcity of evidence based information about disease specific use of antimicrobials such as diarrhea, which has still been considered as second leading cause of childhood mortality and morbidity [6].

The International Center for Diarrheal Disease Research, Bangladesh (icddr,b) maintains a round the clock Diarrheal Disease Surveillance System (DDSS) that systematically enrolls diarrhea patient attending in the two large diarrheal disease facilities in urban Dhaka and rural Matlab irrespective of age, sex and socio-economic status [7]. Thus, the present study aimed to describe urban-rural differentials with regard to socio-demographic characteristics, clinical features, and etiologic distribution in antimicrobials use and identify predictors of antimicrobials use at home before coming to the hospital.

\section{Methods and Materials}

\subsection{Study Site}

The study was conducted among under-5 children visiting the urban Dhaka Hospital and rural Matlab Hospital of icddr, b.

\subsubsection{Dhaka Hospital}

Established in 1963, the Dhaka Hospital, located in urban Dhaka, currently provides cost free care and treatment to around 140,000 diarrheal patients each year. The hospital maintains the DDSS since 1979, and systematically enrolls patients attending the facility $(4 \%$ sample from 1979-1995; and 2\% since 1996), irrespective of age and sex. The DDSS provides valuable information to hospital clinicians in their decision-making process and enables to detect the emergence of new pathogens and in early identification of outbreaks and their locations, thereby alerts the host government to take appropriate preventive and control measures. Extensive microbiological assessments of fecal samples (culture, Enzyme-linked Immunosorbent Assay and microscopy) are performed to identify diarrheal pathogens.

\subsubsection{Matlab Hospital}

Icddr, b maintains a treatment facility in rural Matlab (Matlab Hospital), about 55 kilometres southeast from Dhaka, since 1963. It provides free treatment to 12,000 15,000 diarrhea patients annually reporting from Health and Demographic Surveillance System (HDSS) area and other adjoining sub-districts. The Matlab DDSS has been initiated in 2000, which enrolls all patients coming from the areas of active HDSS of icddr, $b$.

\subsection{Study Participants}

From 2010 to 2012, a total of 8,319 patients and another 4,243 patient were enrolled into the DDSS of urban Dhaka Hospital and rural Matlab Hospital respectively; irrespective of age, sex, socio-economic status and disease severity. Of them, $51 \%(\mathrm{n}=4,245)$ from Dhaka Hospital and $51 \%(n=2,161)$ from Matlab Hospital were aged less than 5 years and constituted the study population.

\subsection{Specimen Collection and Laboratory Procedure}

Single, fresh, whole stool specimen (at least $3 \mathrm{ml}$ or grams, ideally $10 \mathrm{ml}$ or grams) was collected from patients at enrollment. Stool specimens were labeled with the subject's identification number, date and time of collection and sent to the laboratory of Dhaka and Matlab accordingly soon after collection for isolation of etiologic agents including rotavirus [8], Shigella spp. [9], Vibrio cholerae [10], Salmonella spp. [9], Giardia [9], and Entamoeba histolytica [9] following standard laboratory methods.

\subsection{Ethical Statement}

The Disease Surveillance System (DDSS) of icddr, $b$ is a routine ongoing activity of the Dhaka Hospital, and Matlab Hospital which has been approved by the Research Review Committee (RRC) and Ethical Review Committee (ERC) of icddr,b. Informed verbal consent was obtained from all enrolled children's legal caretaker or mother and a check mark was documented during enrollment.

\subsection{Data Analysis}

Statistical analyses were performed using Statistical Package for Social Sciences (SPSS, Chicago, IL version15.5) and Epi Info (Version 6.0, USD, Stone Mountain, GA). Both descriptive and analytical methods were employed. Study children were categorized into two groups considering the use of antimicrobials at home before coming to the hospital: (i) used antimicrobials, and (ii) not used antimicrobials. For categorical variables, differences in the proportion were compared by Chi-square test and strengths of associations were estimated by calculating the odds ratios (OR) with $95 \%$ confidence intervals (CI). A probability of less than 0.05 was considered as statistically significant. Finally, logistic regression analysis was performed to determine the factors that were associated with antimicrobials use. In the present analysis, study site was considered as a potential predictor in addition to other variables of interest that were found to be significantly associated with antimicrobials used in univariate analysis.

\section{Results}

Seventy six percent $(n=3,231)$ under-5 children from urban site and $51 \%(\mathrm{n}=1,094)$ from rural area received antimicrobials at home before coming to the hospital $(p<0.001)$. In urban area, proportion of children aged 0-23 
months, better socio-economic condition (monthly income $>100$ US\$), distance to health facility from home ( $>5$ miles), use of oral rehydration solution (ORS) at home (Table.1) and rotavirus infection (Table.2) were significantly higher among children who used antimicrobials at home before coming to the hospital compared to children who did not use. However, mothers with no formal schooling, and children with a duration of diarrhea for $>1$ day, and Vibrio cholerae infection (Table 2) used antimicrobials less often than children of other group.

Table 1. Socio-demographic and clinical characteristics of used antimicrobials prior to hospital among under-5 children in rural and urban areas of Bangladesh

\begin{tabular}{|c|c|c|c|c|c|c|}
\hline Indicators & $\begin{array}{c}\text { Used } \\
\text { antimicrobials } \\
\mathbf{n = 3 2 3 1}(\%)\end{array}$ & $\begin{array}{r}\text { Urban } \\
\text { Not used } \\
\text { antimicrobials } \\
\mathrm{n}=\mathbf{1 0 1 4}(\%)\end{array}$ & OR; (95\% CI) p-value & $\begin{array}{c}\text { Used } \\
\text { antimicrobials } \\
\mathbf{n = 1 0 9 4}(\%)\end{array}$ & $\begin{array}{c}\text { Rural } \\
\text { Not used } \\
\text { antimicrobials } \\
\mathbf{n}=\mathbf{1 0 6 7}(\%) \\
\end{array}$ & OR; (95\% CI) p-value \\
\hline $0-23$ months & $2906(90)$ & $831(82)$ & $1.97(1.61,2.41)<0.001$ & $953(87)$ & $897(84)$ & $1.28(1.00,1.64) 0.051$ \\
\hline Male Sex & $2036(63)$ & $625(62)$ & $1.06(0.91,1.23) 0.451$ & $661(60)$ & $672(63)$ & $0.90(0.75,1.07) 0.238$ \\
\hline $\begin{array}{l}\text { Illiteracy of } \\
\text { mother }\end{array}$ & $498(15)$ & $231(23)$ & $0.62(0.52,0.74)<0.001$ & $47(4)$ & $70(7)$ & $0.64(0.43,0.95) 0.026$ \\
\hline Family size $(\leq 5)$ & $2161(67)$ & $690(68)$ & $0.95(0.81,1.11) 0.515$ & $609(56)$ & $590(55)$ & $1.02(0.85,1.21) 0.896$ \\
\hline $\begin{array}{l}\text { Number of under- } \\
5 \text { children }\end{array}$ & $3127(97)$ & $982(97)$ & $0.76(0.44,1.32) 0.371$ & $1053(96)$ & $1022(96)$ & $1.14(0.71,1.81) 0.650$ \\
\hline $\begin{array}{c}\text { Monthly } \\
\text { income>100 US\$ }\end{array}$ & $2390(74)$ & $701(69)$ & $1.27(1.09,1.49) 0.003$ & $675(62)$ & $518(49)$ & $\begin{array}{c}1.71(1.43,2.03) \\
<0.001\end{array}$ \\
\hline $\begin{array}{l}\text { Distance of } \\
\text { facility }>5 \text { miles } \\
\text { from residence }\end{array}$ & $2620(81)$ & $683(67)$ & $2.08(1.77,2.45)<0.001$ & $321(29)$ & $256(24)$ & $1.32(1.08,1.60) 0.006$ \\
\hline $\begin{array}{l}\text { Use of ORS } \\
\text { before coming to } \\
\text { hospital }\end{array}$ & $3185(99)$ & $910(90)$ & $\begin{array}{l}7.91(5.47,11.46) \\
<0.001\end{array}$ & $133(12)$ & $280(26)$ & $\begin{array}{c}0.39(0.31,0.49) \\
<0.001\end{array}$ \\
\hline $\begin{array}{c}\text { Duration of } \\
\text { diarrhea (>1day) }\end{array}$ & $581(18)$ & $528(52)$ & $0.20(0.17,0.24)<0.001$ & $284(26)$ & $581(55)$ & $\begin{array}{c}0.29(0.24,0.35) \\
<0.001\end{array}$ \\
\hline $\begin{array}{c}\text { Frequency of } \\
\text { stool }>10 \text { times } / 24 \\
\text { hrs }\end{array}$ & $3110(96)$ & $962(95)$ & $1.39(0.98,1.96) 0.064$ & $236(22)$ & $275(26)$ & $0.35(0.25,0.50) 0.024$ \\
\hline Watery stool & $3110(96)$ & $962(95)$ & $1.39(0.98,1.96) 0.064$ & $881(81)$ & $849(80)$ & $1.07(0.86,1.33) 0.583$ \\
\hline Vomiting & $2040(63)$ & $674(67)$ & $0.86(0.74,1.01) 0.060$ & $789(72)$ & $770(72)$ & $1.00(0.82,1.21) 0.980$ \\
\hline Abdominal Pain & $626(19)$ & $190(19)$ & $1.04(0.87,1.25) 0.684$ & $417(38)$ & $300(28)$ & $\begin{array}{c}1.57(1.31,1.89) \\
<0.001\end{array}$ \\
\hline Cough & $658(20)$ & $197(19)$ & $1.06(0.88,1.27) 0.543$ & $515(47)$ & $663(62)$ & $\begin{array}{c}0.54(0.45,0.65) \\
<0.001\end{array}$ \\
\hline Fever $\left(\geq 37.8^{\circ} \mathrm{C}\right)$ & $290(9)$ & $80(8)$ & $1.15(0.88,1.50) 0.315$ & $98(9)$ & $144(14)$ & $\begin{array}{c}0.63(0.48,0.83) \\
<0.001\end{array}$ \\
\hline
\end{tabular}

On the other hand, in rural area, proportion of children using antimicrobials was significantly more common among children from better socio-economic status (monthly income $>100$ US\$); those travelled longer distance to reach health facility, and presenting with abdominal pain compared to children who did not use. Moreover, those children who tended to receive antimicrobials less frequently were: mothers with no formal schooling; used ORS at home, had shorter duration of diarrhea (less than one day), reported stool frequency more than 10 times $/ 24 \mathrm{hrs}$, and had associated cough and fever (Table 1). No significant differences were observed with etiologies of diarrhea between antimicrobials user and non-users among rural children.
Among the rotavirus infected children, use of antimicrobials was significantly higher in urban children compared to rural children $(47 \%$ vs. $33 \%, \mathrm{p}<0.001)$. Additionally, urban children infected with Vibrio cholerae $(4 \%$ vs. $2 \%, p=0.045)$ also received more antimicrobials than rural area (Table 2). Salmonella, Giardia and Entamoeba histolytica were similarly isolated between urban and rural antimicrobials user and non-user children (Table 2).

In multivariate analysis, urban under-5 children were 1.5 times more commonly used antimicrobials compared to rural children. Similarly, urban children aged 0-23 months, coming from better off families (monthly income $>100$ US\$), covering a distance of more than 5 miles to reach health facility, using ORS at home, having duration of 
diarrhea more than 24 hours, reporting abdominal pain, and presenting with rotavirus infection were more likely to give history of antimicrobials use at home than their counterparts. On the other hand, maternal illiteracy, cough and Vibrio cholerae infection tended to cause less antimicrobials use among study children (Table 3 ).

Table 2. Distribution of pathogen among under-5 children used antimicrobials prior to hospital among rural and urban areas of Bangladesh

\begin{tabular}{|c|c|c|c|c|c|c|}
\hline Indicators & $\begin{array}{c}\text { Used } \\
\text { antimicrobials } \\
\mathbf{n = 3 2 3 1}(\%) \\
\end{array}$ & $\begin{array}{c}\text { Urban } \\
\text { Not used } \\
\text { antimicrobials } \\
\mathbf{n}=\mathbf{1 0 1 4}(\%) \\
\end{array}$ & $\begin{array}{c}\text { OR; }(95 \% \mathrm{CI}) \mathrm{p}- \\
\text { value }\end{array}$ & $\begin{array}{c}\text { Used } \\
\text { antimicrobials } \\
\text { n=1094 (\%) } \\
\end{array}$ & $\begin{array}{c}\text { Rural } \\
\text { Not used } \\
\text { antimicrobials } \\
\mathbf{n}=1067(\%) \\
\end{array}$ & OR; (95\% CI) p-value \\
\hline Rotavirus & $1532(47)$ & $299(29)$ & $\begin{array}{c}2.14(1.83,2.50) \\
<0.001\end{array}$ & $361(33)$ & $322(30)$ & $1.14(0.95,1.37) 0.173$ \\
\hline Shigella & $83(3)$ & $36(4)$ & $0.72(0.47,1.09) 0.123$ & $80(7)$ & $64(6)$ & $1.24(0.87,1.76) 0.255$ \\
\hline Vibriocholerae & $116(4)$ & $82(8)$ & $\begin{array}{c}0.42(0.31,0.57) \\
<0.001\end{array}$ & $25(2)$ & $27(3)$ & $0.90(0.50,1.61) 0.817$ \\
\hline Salmonella & $31(1)$ & $8(1)$ & $1.22(0.53,2.88) 0.758$ & $14(1)$ & $14(1)$ & $0.98(0.44,2.18) 0.901$ \\
\hline Giardia & $4(0.2)$ & $9(1)$ & $\begin{array}{c}0.13(0.03,0.46) \\
<0.001\end{array}$ & $5(1)$ & $10(1)$ & $0.49(0.15,1.55) 0.282$ \\
\hline E. histolytica & $2(0.3)$ & $2(0.1)$ & $0.30(0.03,2.93) 0.226$ & $0(0.0)$ & $2(0.2)$ & $0.00(0.00,3.98) 0.245$ \\
\hline
\end{tabular}

Table 3. Factors associated with use of antimicrobials among under-5 children

\begin{tabular}{cc}
\hline Indicator & $\begin{array}{c}\text { Adjusted OR (95\% CI) p } \\
\text { value }\end{array}$ \\
\hline Study area (urban=1, rural $=0)$ & $1.53(1.24,1.89)<0.001$ \\
$0-23$ months & $1.31(1.08,1.62) 0.011$ \\
Illiteracy of mothers & $0.74(0.61,0.90) 0.002$ \\
Monthly income $>100$ US\$ & $1.34(1.14,1.56)<0.001$ \\
Distance of facility $>5$ miles from & $1.63(1.39,1.90)<0.001$ \\
residence & $2.95(2.23,3.90)<0.001$ \\
Use of ORS before coming to & $4.25(3.67,4.91)<0.001$ \\
hospital & $1.47(1.27,1.69)<0.001$ \\
Duration of diarrhea $(>1$ day) & $1.30(1.03,1.47) 0.023$ \\
Frequency of stool $>10$ times $/ 24 \mathrm{hrs}$ & $0.83(0.70,0.98) 0.027$ \\
Abdominal Pain & $1.02(0.80,1.31) 0.871$ \\
Cough & $1.54(1.32,1.80)<0.001$ \\
Fever $\left(\geq 37.8^{\circ} \mathrm{C}\right)$ & $0.70(0.50,0.97) 0.030$ \\
Rotavirus &
\end{tabular}

\section{Discussion}

In the present study, under-5 children from urban area used antimicrobials more often compared to rural children, which was one of the interesting findings in the context of Bangladesh that again has been supported by other studies observed in recent past $[11,12]$. This can be explained in several ways: easy access to drug stores with availability of frequently used low cost antimicrobials and irrational prescribing practices by the non professionals such as salesman of drug stores as well as better socio-economic status of the families who can afford for the antimicrobials. Other than that, due to lack of legislation that prohibits sales or prescribing of antimicrobials by the non professionals including unlicensed health care providers result in excess use or abuse of antimicrobials.

The present study observed that, literate mothers opted more frequently for antimicrobials for their young children with diarrhea while the illness is known to be self-limiting in most of the cases [13]. Bangladesh has achieved much improvement in maternal literacy as well as increase in national Gross domestic product (GDP) over the last decade [14]. As a result, there is improvement in women empowerment and active participation of women in income generating activities which may influence their decision making process [14]. Because of their too many family commitments with less time to wait, they often go for antimicrobials use in childhood diarrheal illnesses with or without the use of ORS for a considerable period. These might result in their frequent visit to drug stores or sometimes persuasion of health care providers for prescribing antimicrobials. Thus study explains reasons for the practices of frequent use of antimicrobials by well off families. Moreover, same explanations would be true for delay in reporting to facilities by the mothers. It is understandable that seeking care not only depends on disease severity [15] but also on easy access to the health facilities [16]. Mode of transportation and its availability might often hamper care seeking behavior like timely reporting to health facility. Children under-5 years residing in a place more than 5 miles away from the hospital were found to use antimicrobials more frequently at home. Mothers too far from the health facilities were more likely to visit nearby drug stores for seeking care for their young children. Likely explanations might be: longer distance which is an important obstacle to proper treatment at health facility for under-5 children due to scarcity of transportation and poorly structured roads in rural area. Previous studies found that, children living close to the 
health facilities had a $50 \%$ higher chance to get immunized than others who are far from facilities [17, 18]. Another probable explanation might be that they first try at household level with apparently low cost therapies obtained from health care provider which often includes antimicrobials.

Moreover, concurrent use of ORS and antimicrobials was another interesting observation. This actually illustrated the universal use of ORS which is considered as life saving solution that reduces the sufferings of diarrheal illness as well as excess burden on health facility and decreases dehydrating diarrhea related mortality [19]. Mass media campaigns often influence more use of ORS for treating childhood diarrhea [20,21]. Unfortunately, clinical manifestations such as abdominal pain [22] and frequent passage of stool ( $>10$ times/24hours) were basis for mothers to use antimicrobials more frequently at home. Inappropriate use and misuse not only increase the resistant pattern but also cause superimposed infection due to bacterial overgrowth and reduce intestinal flora in addition to hypersensitivity and drug toxicity [23-25]. At the same time, with early resolution of diarrhea, parents often feel reluctant to comply with the drug regimen in appropriate dose and duration.

Considering etiology, most of the studies documented rotavirus as most frequently causing childhood diarrhea [26, 27]. Antimicrobials use was higher both in urban and rural areas in rotavirus diarrhea compared to other enteric pathogens. This is really an alarming public health issue where there is no rational for use of any antimicrobials for treating rotavirus diarrhea cases. Though Vibrio cholerae infection is less common among under-5 children, but sudden and rapid loss of water and electrolytes may lead to some or severe dehydration or even life threatening hypovolaemic shock $[28,29]$. Parents may not wait at home for treatment with ORS and zinc; rather visit the health facility more often. This is why use of antimicrobials was lower in both the study sites in case of cholera among young children. On the other hand, other pathogens such as Salmonella, Giardia and Entamoeba histolitica were equally distributed with very lower isolation rate. Thus, diarrhea due to these pathogens may not affect the use of antimicrobials at home.

\section{Conclusions}

The present study documented several sociodemographic and clinical manifestations that might have influences on the use of antimicrobials before coming to the health facility. Although, childhood diarrhea is a self limiting disease and broadly known to contribute as an emerging public health burden in Bangladesh; use of irrational antimicrobials and increasing resistance to antimicrobials are alarming public health threat. A national guideline for proper use of antimicrobials as well as implementation of legislation with its proper monitoring under the guidance of policy makers is extremely important.

\section{Limitations}

Unbiased systemic sampling methods to enroll patients into surveillance system irrespective of age, sex, nutritional status, disease severity, socio-economic background; and the large dataset with standard laboratory facility were strengths of the present study. However, lack of detailed information about treatment received and type of antimicrobials used at household level has added bias which might have influenced our findings.

\section{Competing Interest}

There is no potent conflict of interest to declare. All authors confirm that there is no professional affiliation, financial agreement or other involvement with any company whose product figures prominently in the submitted manuscript.

\section{Acknowledgements}

Hospital surveillance was funded by icddr,b and the Government of the People's Republic of Bangladesh through IHP-HNPRP. Icddr, b acknowledges with gratitude the commitment of the Government of the People's Republic of Bangladesh to icddr, b's research efforts. Icddr, $\mathrm{b}$ also gratefully acknowledges the following donors which provide unrestricted support to the Centre's research efforts: Australian Agency for International Development (AusAID), Government of the People's Republic of Bangladesh, Canadian International Development Agency (CIDA), Swedish International Development Cooperation Agency (Sida), Swiss Agency for Development and Cooperation (SDC), and Department for International Development, UK (DFID).

\section{References}

[1] Antimicrobial use. Drug resistance. Geneva. WHO. http://www.who.int/drugresistance/use/en/ 2013.

[2] Holloway, K. and L. van Dijk, Rational use of medicines, in the world medicines situation 2011. 2011, WHO: Geneva.

[3] Rational use of medicines. Medicines. http://www.who.int/mediacentre/factsheets/fs338/en/.Genev a. WHO. 2010.

[4] The pursuit of responsible use of medicines: sharing and learning from country experiences, medicine, http://www.who.int/medicines/publications/responsible_use/ en/ Geneva, WHO. 2012.

[5] Options for action, The evolving threat of antimicrobial resistance. 2012, WHO: Geneva.

[6] Has an R, et al., Pattern of antibiotics use at the Primary Health Care level of Bangladesh: Survey report-1. Stamford 
Journal of Pharmaceutical Sciences, 2009. Vol.2(1) p. 1-7. DOI: $10.3329 /$ sjps.v2i1.5809

[7] Das, S.K., et al., Etiology of diarrhea among severely malnourished infants and young children: observation of urban-rural differences over one decade in Bangladesh. Food and Nutrtion Sciences., 2013. Vol. 4: p. 233-239. DOI:10.4236/fns.2013.43031

[8] Rahman, M., et al., Genetic characterization of a novel, naturally occurring recombinant human G6P[6] rotavirus. J Clin Microbiol, 2003. 41(5): p. 2088-95.

[9] WHO. Manual for laboratory investigations of acute enteric infections. Geneva: Programme for control of diarrhoeal disease: World Health Organization;. 1987.

[10] Qadri, F., et al., Production, characterization, and application of monoclonal antibodies to Vibrio cholerae O139 synonym Bengal. Clin Diagn Lab Immunol, 1994. 1(1): p. 51-4.

[11] Kumar, R., et al., Antibiotic prescribing practices in primary and secondary health care facilities in Uttar Pradesh, India. J Clin Pharm Ther, 2008. 33(6): p. 625-34. DOI:10.1111/j.1365-2710.2008.00960.x

[12] Sharma, M., et al., Antibiotic prescribing in two private sector hospitals; one teaching and one non-teaching: a cross-sectional study in Ujjain, India. BMC Infect Dis. 12: p. DOI:155.10.1186/1471-2334-12-155

[13] Ansari, S., et al., Characterization of rotavirus causing acute diarrhoea in children in Kathmandu, Nepal, showing the dominance of serotype G12. J Med Microbiol, 2012. 62(Pt 1): p. 114-20. DOI:10.1099/jmm.0.048124-0

[14] National Report of Bangladesh, Development of Education,Ministry of Education, http://www.ibe.unesco.org/International/ICE47/English/Natr eps/reports/bangladesh.pdf. 2004.

[15] Das, S.K., et al., Health Care-Seeking Behavior for Childhood Diarrhea in Mirzapur, Rural Bangladesh. Am J Trop Med Hyg, 2013 DOI:10.4269/ajtmh.13-0107

[16] Ferdous, F., et al., The impact of socio-economic conditions and clinical characteristics on improving childhood care seeking behaviors for families living far from the health facility Science Journal of Public Health, 2013. 1(2): p. 6976. DOI:10.11648/j.sjph.20130102.14

[17] Bhuiya, A., et al., Factors affecting acceptance of immunization among children in rural Bangladesh. Health
Policy Plan, 1995. 10(3): p. 304-12.

[18] Rahman, M. and S. Obaida-Nasrin, Factors affecting acceptance of complete immunization coverage of children under five years in rural Bangladesh. Salud Publica Mex, 2010. 52(2): p. 134-40. DOI: S0036-36342010000200005

[19] Ellis, A.A., et al., Home management of childhood diarrhoea in southern Mali--implications for the introduction of zinc treatment. Soc Sci Med, 2007. 64(3): p. 701-12. DOI: S0277-9536(06)00521-1

[20] Larson, C.P., et al., Scaling up zinc treatment of childhood diarrhoea in Bangladesh: theoretical and practical considerations guiding the SUZY Project. Health Policy Plan, 2012. 27: p. 102-14. DOI:10.1093/heapol/czr015

[21] Larson, C.P., et al., Impact monitoring of the national scale up of zinc treatment for childhood diarrhea in Bangladesh: repeat ecologic surveys. PLoS Med, 2009. 6(11): p. e1000175. DOI: 10.1371/journal.pmed.1000175

[22] Yoder, P.S. and R.C. Hornik, Symptoms and perceived severity of illness as predictive of treatment for diarrhea in six Asian and African sites. Soc Sci Med, 1996. 43(4): p. 429-39. DOI: 0277953695004084

[23] Seddon, M.E., et al., The Adverse Drug Event Collaborative: a joint venture to measure medication-related patient harm. N Z Med J, 2010. 126(1368): p. 9-20

[24] Star, K., et al., Suspected adverse drug reactions reported for children worldwide: an exploratory study using VigiBase. Drug Saf, 2011. 34(5): p. 415-28.5. DOI:10.2165/11587540-000000000-00000

[25] Kulauzov, M., et al., Sensitivity of bacteria to antimicrobial drugs and interpretation of results. Med Pregl, 2010. 63 Suppl 1: p. 17-21

[26] Leidel, J., et al., Infectious gastroenteritis in childhood. Monatsschr Kinderheilkd, 1982. 130(5): p. 287-91

[27] Bhardwaj, A., et al., Does Rota virus infection cause persistent diarrhoea in childhood? Trop Gastroenterol, 1996. 17(1): p. 18-21.

[28] Kanungo, S., et al., Clinical, epidemiological, and spatial characteristics of Vibrio parahaemolyticus diarrhea and cholera in the urban slums of Kolkata, India. BMC Public Health, 2012. 12: p. 830. DOI:1471-2458-12-830

[29] Pastore, G., Treatment of cholera in the adult. Studies during recent epidemics in Apulia. Ann Sclavo, 1975. 17(3): p. 399-418. 